\section{LA PRIMERA UNIVERSIDAD DEL CARIBE COLOMBIANO - UN MODELO ILUSTRADO PARA AMÉRICA COLONIAL}

\section{Diana Soto Arango*}

RESUMEN: Este trabajo se propone analizar el proceso de organización y aprobación del Colegio-universidad de San Pedro Apóstol que se aprobó por Cédula Real en 1806, en la Villa de Mompox. Se demostrará como esta institución presenta la característica de tener una Constitución de carácter ilustrado que fue elaborada por Eloy Valenzuela. Por otra parte, la probación, por parte del Rey, del nuevo colegio-universidad dependió de la influencia política de Dn Pedro Pinillos y del dinero que le dio este a la Corona Española. El artículo se fundamenta en la metodología de la historia social de la educación baseada en fuentes primarias, fundamentalmente, del Archivo General de la Nación Colombia (AGN) Y el Archivo General de Indias de España (AGI).

\section{Introducción}

El desarrollo educativo-cultural del Caribe en el virreinato de la Nueva Granada no se puede analizar sin estudiar el desarrollo económico de la Provincia de Mompox. En especial, implica el análisis de varios factores desde la excelente ubicación geográfica, la elite comerciante momposina con la rivalidad cartagenera y la incidencia del grupo de la 'Expedición Botánica' en la Villa de Santa Cruz de Mompox.
PALABRAS-CLAVE: universidad colonial; reformas universitarias; constituciones; Caribe colombiano. *Profesora de Escuela de
Sociales; Doctorado Ciencias de
la Educación de RuDECOLOMBIA;
Co-directora del proyecto
"Historia y prospectiva de la
universidad Latinoamericana".
dianasoto@007mundo.com 
${ }^{1}$ La Villa de Santacruz de Mompox fue fundada por Pedro de Heredia en 1537 con la categoría de puerto fluvial. Cartagena se había fundado en 1533. Se le consideró Provincia separada de Cartagena por Real Cédula del 3 de agosto de 1774. Pero la misma se revocó en 1777 por la influencia de la élite de Cartagena. En adelante señalaremos sólo como la Villa de Mompox.
Por lo anterior, la gran pregunta qué nos hacemos es de ¿Cuáles fueron los factores que incidieron para qué en la Villa de Mompox se estableciera ColegioUniversidad con aprobación Real en 1806 y por qué esta situación no se dio en Cartagena principal epicentro de desarrollo en el Caribe de la Nueva Granada? Esta gran pregunta estará presente en la perspectiva de análisis que daremos a conocer en este trabajo.

Las fuentes se localizan principalmente en el Archivo General de la Nación - AGN y luego en bibliografía secundaria recogida en el periódico $L a$ Voz de Mompox.

\section{El Colegio-Universidad de San Pedro Apóstol: un producto de la bonanza comercial de la Villa de Mompox y de la incidencia del grupo de la Expedición Botánica}

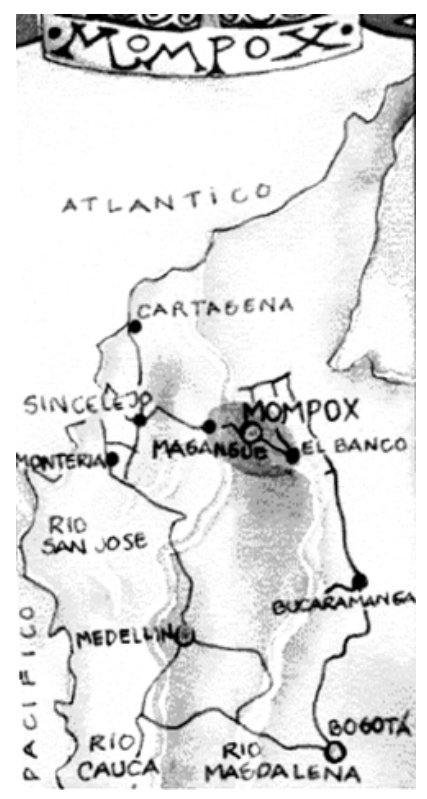

En nuestro análisis caracterizamos tres elementos que incidieron en este hecho de transformación cultural en la Villa de Mompox.

En primera instancia, señalamos que el desarrollo cultural y social de la villa de Santa Cruz de Mompox ${ }^{1}$ está unido al desarrollo económico de la misma y al enfrentamiento político-comercial que se daba con la ciudad de Cartagena. Sin lugar a dudas el epicentro era Cartagena pero Mompox creada sólo cuatro años después en 1537 se convirtió pronto en la segunda ciudad del Caribe en población y movimiento económico-comercial.

Por lo anterior, se incluye en el análisis el hecho significativo que en el censo de población de 1780, en la Provincia de Cartagena, la segunda ciudad más poblada era la villa de Santacruz de Mompox con 7.093 habitantes mientras Cartagena tenía 13.387 y la capital Santafé con 24 miles. Lo 
relevante es que Mompox después de Cartagena tenía el mayor número de esclavos (837) pero presentaba un escaso número de indios que sólo llegaban a 77. En la categoría de personas libres alcanzaba el número de 5.248 donde es posible este concentrado el mayor número de comerciantes en mestizos y mulatos. Sin embargo, en el estrato blanco Mompox ocupaba el tercer lugar (878) después de Cartagena y Lorica. Para nuestro análisis lo significativo se localiza en una fuerte élite criolla comercial que se había educado a finales del siglo XVIII en la capital santafereña.

Hay un aspecto que conviene señalar en la fundación del Colegiouniversidad y es el del desarrollo de la villa de Mompox para entender el auge educativo de comienzos del siglo XIX en esta villa. En este caso, como señala Georges Duby (apud Conde CALDERÓn, 1999, p. 16) la ciudad se caracteriza por "rasgos particulares de status jurídico, de sociabilidad y de cultura. El papel no es económico es político". Sin embargo, en las "últimas décadas coloniales el concepto de urbanización empezó a significar progreso de las ciudades y pueblos, reestructuración financiera, mejoramiento de los servicios urbanos y mayor control de la moralidad y del comportamiento de sus habitantes" (GARRIDO, 1993, p. 203). Este ideal de progreso para Mompox lo personificó a finales del siglo XVIII Dn Pedro Pinillos.

Hay que decir, que en las colonias españolas las ciudades tenían una finalidad en relación a "privilegiar los intercambios con la metrópoli lejana" (CONDE CAlderón, 1999, p. 16). Por este motivo considera Conde que la villa de Mompox se creo "en la banda izquierda del río Magdalena, límite natural de las gobernaciones de Cartagena y Santa Marta" (Ibidem). Ahora bien, el puerto fluvial de Mompox sobre el río Magdalena se convirtió en el centro administrativo de los pueblos del bajo Magdalena y además se constituyó en el "centro de equilibrio entre los comerciantes y terratenientes y entre los antiguos y los nuevos pobladores quienes competían por la propiedad de la tierra y de los hatos" (GARRIDO, p. 207208). Como hemos visto, reiteramos que la villa de Mompox, a finales del siglo XVIII, se caracterizó por el intenso comercio y por ser uno de los puertos más importantes sobre el río Magdalena. Era el sitio obligado para los mercaderes procedentes de Cartagena, Santa Marta y Riohacha y para los que venían del centro del país através de Honda. Allí se concentraba el comercio de esclavos, el 
del oro, con el de las mercancías de telas y productos vegetales como la quina y el tabaco. Se describe a Mompox a comienzos de 1810 como una Villa de "14.000 habitantes, tres escuelas primarias, la nueva universidad, un clero numeroso e ilustrado[...] y era esta villa el gran mercado de oro y otros productos del país, y el gran depósito de donde los pueblos del interior se proveían de mercancías europeas" (ANALES DEL EsTADO DE BOLÍVIAR, s/f).

No es extraño, por lo tanto, que en 1784 se solicitara la creación del Consulado de Mompox con su director Gonzalo José de Hoyos y que en este mismo año se fundará en esta Villa la primera Sociedad de Amigos del País de América colonial. No cabe duda que en estos aspectos marco el liderazgo la villa de Mompox frente al desarrollo que llevaba Cartagena. En concreto, Cartagena trato de fundar en 1787 una Sociedad Económica con la denominación de Sociedad de amigos del País de Turbaco, para apoyar el cultivo del algodón sin lograrlo como lo señala Pedro Fermín de Vargas (1986) y sólo consiguió el Consulado en 1795. Por el contrario, debemos indicar que la Sociedad de Amigos del País de Mompox "creó corresponsales y apoderados en todo el Reino con el apoyo del virrey Caballero y Góngora" (SALCEDO Del VILLAR, 1987, p. 16). Además, se nombró miembro de honor al sabio Mutis quien estaba unido a esta ciudad por ser el sitio de residencia de su hermano y también porque había estado en la misma desde su llegada al Virreinato en 1762 y posteriormente también se había desplazado a la Villa a realizar un estudio sobre el terreno y el cambio de lugar del cementerio.

En definitiva, esta comparación final sirve para aclarar que la Villa de Mompox era un centro comercial de relevancia en el virreinato y en la costa Caribe con nexos y apoyos en la capital. Sólo resta decir que el contrabando se había convertido en una línea comercial de mayor flujo económico. Pero antes de terminar, un tema que nos lleva a una gran pregunta es de ¿qué factores incidieron para que esta villa apartada en el continente americano se convirtiera en pionera de una de las Instituciones de la Ilustración como eran Las Sociedades Económicas de Amigos del País? Porque si bien es cierto que la villa de Mompox era relevante para nuestro virreinato por las características señaladas anteriormente de ello no se deduce una importancia en el conjunto de la colonia española en América. Es bien sabido que el virreinato de la Nueva Granda, a 
comienzos del siglo XIX (MingueT, 1985), sólo exportaba dos millones de pesos en productos agrícolas y tres millones en oro y plata. E importaba en mercancías 5,7 millones de pesos. Esta importación y exportación era irrelevante si la comparamos con el virreinato de Nueva España que importaba veinte y dos millones y exportaba 31,5 millones o en el Virreinato del Perú que importaba 11,5 millones y exportaba 12 millones (id.ib.). No es este el lugar adecuado para analizar las cifras económicas pero es relevante señalar que para 1804 el producto bruto de las colonias americanas era de 36 a 38 millones (id. ib.) de pesos mientras el de la metrópoli era inferior con la suma de 35 millones.

Un segundo aspecto, que contribuye a explicar la organización de la universidad en la villa de Mompox se refiere al hecho de localizar en esta ciudad al comerciante español Pedro Martínez Pinillos (1748-1809) quien llegó a la villa en 1770 y permaneció en la misma por casi 39 años (1770-1809). Es importante señalar que desde comienzos del siglo XVIII se había superado la resistencia de los españoles y criollos en considerar el comercio un oficio vil. Por el contrario ahora los comerciantes eran un sector determinante y con influencias en la Corte por las donaciones que realizaban al Rey. En efecto, para esta época el español comerciante Pedro Pinillos tenía un reconocimiento y prestigio en la Corona y el virreinato. Según se ha podido establecer, fue significativo, el privilegio que le otorgó la Corona española para ser el único importador de Mercancías para esta Villa y por Real Orden, del 2 de noviembre de 1792, se le eximió del pagó de impuestos por la importación y exportación de productos a la metrópoli (Zambrano Arias; Miranda DE LEON, 1999). Como es de suponer esta situación de privilegio le permitió ocupar y comprar los cargos más distintivos de la Villa. Podemos señalar el de Regidor Alcalde Mayor Provincial de la Villa de Mompox por el valor de 400 pesos a finales de 1787. Pero lo fundamental es que siempre cumplió con las donaciones puntuales para el Rey. Así por ejemplo, lo vemos donando seis casas para obtener del Rey Carlos IV la Real Cédula, del 29 de diciembre de 1800, que elevara de rango la cofradía de Mompox. En este punto es importante indicar que las cofradías se convirtieron en un medio de estrechar vínculos comerciales. Así pues, retomando el hilo conductor de las donaciones de Dn Pedro Pinillos, que posiblemente incidió en las peticiones que realizaba a la Corte, no cabe duda que 
el hecho de donar 5 miles pesos en 1802 para apoyar al rey en su guerra contra Francia e Inglaterra le hizo ganar puntos en su petición de aprobación Real para el Colegio-Universidad de Mompox.

Ahora bien, otro aspecto singular se enmarca dentro del proceso de secularización de la educación superior que había iniciado el fiscal Francisco Moreno y Escandón en la ciudad de Santafé en 1768. En este sentido el citado colegio-universidad para la villa de Mompox tenía como objetivo formar a la población civil y se establecía que el patronato real fuera administrado através del Ayuntamiento de la Villa. Conocemos que en la villa de Mompox la educación estuvo sin mayor desarrollo y hasta 1767 las expectativas educativas las cubría el Colegio de San Carlos de la Compañía de Jesús que fundaron en 1644. Pero es bien conocido que con la expulsión de los jesuitas en 1767 la élite criolla quedó en esta región sin ningún centro educativo para educar a sus hijos. Es por ello que, se iniciaron las clases con tutores pero no existía un centro educativo que acreditara esta educación particular. En realidad era una necesidad vital la organización de un centro educativo que evitará el desplazamiento de los jóvenes a la capital. Hemos localizado que en el sólo Colegio de San Bartolomé se presentó un número considerable de matricula de alumnos provenientes de la Villa de Mompox en la década de los años 70. Por ejemplo en el año 1778 se matricularon 20. Así pues, el mayor problema de otorgar una educación superior a los hijos de la élite de la villa era de difícil solución.

Como señalamos al inicio nuestro interés se centra en entender las condiciones socio-políticas que dan origen al Colegio de San Pedro Apóstol y en especial al carácter Ilustrado del mismo. No podemos dejar de lado que se requería de un mecenas que donará el dinero para la fundación y por otra unas Constituciones avaladas por el virrey que no cayeran en la burocracia administrativa de la Corte. Es bien conocido que todas las reformas ilustradas que se enviaron a la Corte nunca regresaron con el aval Real a las colonias americanas.

Planteadas así las cosas, hay que decir, que el español Pedro Martínez Pinillos logró con los apoyos del Cabildo en Mompox, del virrey de Nueva Granada y sus contactos en la Corte que se expidiera Cédula real para la fundación del Colegio-Universidad de San Pedro-Apóstol en la villa de Mompox constituyéndose en un modelo de institución ilustrada para toda 
América colonial. Llama la atención que el trámite de la solicitud de fundación del colegio-universidad tenía sus apoyos en la Corte porque no deja de ser significativa la rapidez con la que se expide la Real Cédula si se tiene en cuenta la lentitud administrativa de la época. La Real Cédula le concedió al Colegio el privilegio de otorgar grados al establecerla como universidad. Decía la Real Cédula:

Visto todo lo referido a mi Consejo de Indias con lo que informó su contaduría general [...] he venido en acoger bajo mi soberana protección y aprobar las dichas fundaciones y en mandar se erija en universidad el referido colegio, con las mismas facultades y prerrogativas que el de esa capital, vistiendo sus colegiales igual beca con el escudo de su titular San Pedro y facultad de conferir en ella los grados en las facultades que se cursen en la misma universidad. (SALCEDO DeL VILLAR, 1987, p. 113).

Retomando el concepto de progreso de las ciudades y pueblos en la Villa de Mompox lo lideró don Pedro Pinillos a finales del siglo XVIII. Se le ha reconocido por la reconstrucción y donaciones a los templos de Mompox. Por ejemplo al templo de San Agustín le realizó donaciones por 40 miles de pesos (ZAMBRANO ARIAS; Miranda DE LeON, 1999, p. 29-333). Fundo el hospicio, enladrilló la calle de la Contaduría, dio donaciones a la cárcel. En 1793 con el incendio y en 1803 con el desbordamiento del río Magdalena se encargó de la recuperación de la gente y de sus casas. El 31 de octubre de 1801 compró a la Real Hacienda española la Casa colegio de los Jesuitas. Allí instaló el Hospicio, el hospital de Jesús y el Colegio de San Pedro. Al año siguiente, en 1802, destinó 176,5 miles de pesos para la creación de dos escuelas de primeras letras en los barrios San Francisco y Santa Bárbara.

Debemos indicar que el citado Colegio inició estudios con 6 becas en 1802. Se enseñaba latinidad, filosofía y teología. Por lo anterior, no es de extrañar que posteriormente luego de inaugurada la universidad, el 29 y 30 de agosto de 1809, a escasos cinco meses empezará a otorgar grados. En concreto, en el mes de enero de 1810 se inicia el proceso de graduación a los estudiantes en la nueva Universidad. La única explicación que tenemos es el hecho de haber validado los estudios del antiguo colegio. El primer grado que se otorgó fue el de Bachiller en Filosofía al estudiante Eugenio de la Torre y Corral el 17 de enero 
de 1810. Pero luego, el 19 de enero se lo expiden a Tomás Germán Ribón e la misma área. Pero en octubre de ese año se expiden grados en Bachiller y licenciados en Teología y Cánones. Es más, se otorgó grado de doctor en Teología y Derecho Canónico a tres estudiantes (op. cit. 1999, p. 62-63).

Hasta ahora se ha comentado de las condiciones socio-políticas que originaron el hecho de crear universidad en la villa de Mompox. Pero hay que subrayar que esta universidad se creo con unas Constituciones y un Plan de Estudios de los más avanzados que se plantearon en América colonial. Ciertamente, el tercer aspecto, al cual nos referimos al comienzo de este trabajo se relaciona a la influencia del grupo de la Expedición Botánica en la creación del Colegio-Universidad de Mompox.

\section{El Colegio-Universidad de San Pedro Apóstol un proyecto de un grupo ilustrado en los albores de la nueva República.}

Hemos comentado dos condiciones especiales para la fundación del Colegio-Universidad. Pero además, lo que se debe resaltar es que la propuesta fue una de las más avanzadas en las colonias americanas que logró aprobación Real y aplicación por un corto período de tiempo.

Es significativo, en primera instancia, destacar la incidencia de José Celestino Mutis (1732-1808) en este proyecto educativo. El gaditano había llegado al virreinato en 1760 en calidad de médico del virrey Messia de la Cerda. Como el mismo lo manifiesta los dos primeros años se le fueron en atender a los enfermos de la capital virreinal pero sus intereses eran otros y así se lo manifestó al virrey en las dos representaciones que envío al Rey Carlos III para "La realización de la historia natural de América" (SOTO ARANGO, 1989, p. 87-91).

Mutis en los citados documentos expresaba el ambicioso proyecto que posteriormente sería la Expedición Botánica. Es imprescindible señalar que estos planteamientos de Mutis serían el feliz comienzo de una nueva etapa en el virreinato. La investigación de la naturaleza americana con la finalidad de "saber y conocer las producciones admirables con las que la divina Providencia ha enriquecido los dilatados dominios que tiene la fortuna de vivir bajo la feliz 
dominación de vuestra majestad en este nuevo mundo" (DocumENTOS, 1983, p. 127) estaba acompañado de la creación de un gabinete de historia natural que reuniese ejemplares de plantas, objetos y minerales que se encontrasen en el Nuevo Mundo. No se puede olvidar que es el siglo de las expediciones científicas al nuevo mundo. Francia y Alemania se adelantaban en este proyecto. Pero además, estaba el beneficio económico que podría extraerse de la cochinilla, maderas finas, yerbas bálsamos y otras plantas útiles. Sin embargo, este proyecto sólo se haría realidad 20 años más tarde con la real Cédula de 11 de noviembre de 1783 bajo el auspicio del Virrey Caballero y Góngora, protector de Mutis.

No es nuestro objetivo realizar un estudio de la Expedición Botánica de Mutis pero diremos que la trascendencia fue copernicana en el virreinato. Alrededor de Mutis se congregó la élite Ilustrada y la influencia repercutió en todo el virreinato. El grave problema que afrontó la expedición era el de personal preparado para realizar las observaciones botánicas. Dentrode este contexto se tiene que ver el Plan de Estudios de Moreno y Escandón para Santafé. Pero como es conocido este Plan sólo se aplicó por cinco años. En este sentido la oportunidad se presentó nuevamente cuando don Pedro Pinillos solicita a Mutis que le recomiende a una persona para elaborar las Constituciones del ColegioUniversidad para la villa de Mompox.

En este punto se debe recordar que Mutis ya estaba ligado a la villa de Mompox por medio de su hermano que había establecido negocios en esta ciudad. Por este motivo, y por haber estado en la villa durante dos épocas diferentes conocía los intereses y necesidades de la región. Es precisamente a Mutis a quien le piden que señale el nombre de quien se encargaría de elaborar las Constituciones y Plan de Estudios para la nueva Institución educativa. Desde luego, era una oportunidad para él y su grupo el poder cristalizar las ideas ilustradas que venían tratando de introducir infructuosamente, de una manera institucional, en la enseñanza de los colegios de la capital. Aún estaba en la palestra la polémica suscitada por la defensa de las teorías de Newton y Copérnico que había realizado el mismo Mutis en el Colegio Mayor del Rosario en 1773. Posteriormente, varios catedráticos siguiendo sus pasos trataron de realizar conclusiones públicas sobre este mismo tema con la consecuencia de 
haber perdido sus cargos y haber sido amenazados de expulsarlos de la ciudad. La situación no era fácil. Aún más, recientemente en 1801 los agustinos calzados habían requerido del permiso del virrey para poder exponer públicamente en conclusiones públicas el sistema copernicano.

Hay todavía otro aspecto que conviene destacar y es el hecho de formar personal para la Expedición Botánica y era la oportunidad de realizar un estudio botánico en una región que estaba sin influencia directa en los estudios de la Expedición. Es por ello que se requería de proponer un nombre que tuviese respeto académico y que no fuese acusado de proponer teorías o ideas en contra de la monarquía. La persona recomendada fue el cura Eloy Valenzuela (1756-1834).

Para entender la propuesta se debe conocer quien era Valenzuela. Pero además, lo significativo es que toda la propuesta ilustrada fue avalada con su firma por Pedro Pinillos y de esta manera salió para el respectivo trámite ante: Cabildo de Mompox, gobernador, Virrey, Consejo de Indias y finalmente la anhelada Cédula Real. En efecto, Eloy Valenzuela llega de la mano de Mutis en 1770 al Colegio Mayor del Rosario del que se hace catedrático de Filosofía en 1777 para explicar bajo la Reforma de Moreno y Escandón la nueva filosofía Ilustrada. No fue un azar el hecho que en esta reforma el estudio de las matemáticas se hiciera obligatoria porque se intentó dar una formulación científica al conocimiento, al pretender introducir una nueva enseñanza, cuyos contenidos estaban basados en el conocimiento experimental.

Hay que destacar que el tiempo de docencia de Eloy Valenzuela fue corto pero impacto por la dedicación a sus estudiantes y los contenidos de sus enseñanzas basados en la física experimental y en Newton que los venía explicando José Celestino Mutis en el Colegio Mayor de Rosario. Don Joaquín Escobar, vice-rector del Colegio del Rosario describe que el catedrático Valenzuela "había cumplido su ministerio con tanta exactitud [...] que con cuyo tesón logró instruir a sus discípulos en los tratados de lógica crítica, aritmética, álgebra, geometría y secciones cónicas, los que sustento con ellos en dos públicas conclusiones" (ACMR, v. 125, Libro $1^{\circ}$ de Colegiales, fls. 8 a 10).

Hay, sin embargo que mencionar los contenidos de las conclusiones públicas que dirigió el catedrático Valenzuela y los nombres de sus alumnos que 
luego sobresalieron en la actividad académica de los Colegios y en la política nacional. En el primer año defendió en dominicales con "Ignacio Tejada las preliminares de lógica. Las segundas de aritmética con José Antonio Rota. Las terceras de álgebra con José Antonio Ramón González y dos más con Rota la geometría con González la trigonometría" (Ibidem, fl. 8). En 1778 defendió en las dominicales las siguientes conclusiones públicas: con Pedro Fermín Vargas las preliminares de física; con Fernando Vergara varios capítulos sobre la naturaleza y atributos del cuerpo en particular, con Juan de la Rocha los elementos de la mecánica en castellano; con Tadeo Cabrera "el sistema newtoniano sobre los colores y la heterogeneidad de la luz."(Ibidem, fls. 9-0).

Ya hemos valorado en otros trabajos el éxito del Plan de Estudios de Moreno y Escandón que no puede considerarse como un mero episodio educativo de la ciudad de Santafé. En cierto sentido, diríamos que en esta época se presenció un cambio ideológico en algunos sectores de la elite de colegiales y catedráticos, que se convirtieron en agentes activos del progreso, principalmente para cambiar la mentalidad que se tenía frente a la concepción de las ciencias. Sin embargo, el sector que se oponía a la reforma del Plan de Estudios no compartía estos progresos. Para ellos la aplicación del nuevo método significaba retroceso y caos para el Virreinato. El rector del Colegio del Rosario, quien ya desde 1775 había presentado una propuesta paralela a la del fiscal Moreno, precisa la situación como "triste y de última ruina" (Ibidem, fl. 5v). Este rector señala que la causa principal de esta situación se debe a la aplicación del Plan de Moreno, "por ser sumamente perjudicial" (Ibidem, fl. 5v), y principalmente por haberse ordenado que no se jurará doctrina alguna. Para el rector esta nueva norma iba en contra de las Constituciones de Colegio que señalaba que se debía jurar la doctrina de Santo Tomás. De todas maneras se debe tener presente que este rector no estaba solo porque un grupo del claustro colegial le apoyó para solicitar que se volviera al antiguo Método (AGI, Sección Quinta, Audiencia de Santa Fé, leg. 759).

También era evidente que la situación política-educativa había cambiado en el Virreinato con el apoyo que el visitador Gutiérrez de Piñeres le otorgaba a la comunidad de Santo Domingo y en efecto el Plan de Moreno se suspendió por la Junta de Estudios del 16 de octubre de 1779 (ICFES, 1981, p. 120). Esta 
Junta ordenó que se enseñara y explicara la filosofía del método escolástico. Como era de esperar Eloy Valenzuela se retira de la vice-rectoría del Colegio de Rosario y entra a trabajar con el arzobispo Caballero y Góngora quien le ordena de sacerdote y trabaja con éste en el cargo de secretario.

Conviene destacar que la influencia de José Celestino Mutis sobre Eloy Valenzuela fue permanente. De hecho, cuando se aprueba la Expedición Botánica, en 1783, Mutis lo vincula como sub-director de ésta y le traslada a Mariquita. Es allí donde escribe el Primer diario de la Expedición Botánica del Nuevo Reino de Granada. En esta obra describe el viaje que realizó desde Santafé hasta la citada población de Mariquita en donde permaneció durante un año en sus investigaciones botánicas. Valenzuela siguió los pasos de su protector Mutis en lo académico y religioso. Asimismo, retomando su tarea de sacerdote se retira al curato de Bucaramanga donde desarrolla una labor loable en el desarrollo de la región y en el estudio y descripción de plantas de la zona. En esta población desarrollo tareas propias de un administrador ilustrado de la Corona, entre otras, "la erección de un nuevo templo, la construcción de caminos, el incremento de la agricultura, mejorando la calidad de los pastos y de las especies de caña dulce"(Acevedo Díaz, 1944, p. 235). Podríamos añadir que su convicción de una nueva política para el desarrollo del reino le llevó a costear el camino de Bucaramanga a la aldea de Chita para traer la sal (Ibidem, p. 227-259).

Como puede verse, através de sus escritos, no sólo investigó las plantas sino que también propuso los medios para mejorar la producción y la calidad. Entre sus obras conocidas podemos citar:

- Informe del cura de Bucaramanga sobre reducir los caseríos del campo a poblaciones urbanas. Bucaramanga, 30 de agosto de 1802.

- Flora de Bucaramanga. Bucaramanga, 1808.

- Noticia de una especie de Grama útil para potreros o prados artificiales, 1809.

- Noticia sobre la caña solera, 1809.

- Noticia de una mina de alumbre y otros fósiles, 1810.

- Plana estadística del curato de Bucaramanga, 1828-1832-1833. 
Nos interesa reseñar aquí la extensa correspondencia botánica que sostuvo con José Celestino Mutis. Esta relación epistolar es amplia y de ella hace gala el sabio gaditano al señalar que "descansa mi corazón cuando hablo con Ud. Cada carta de Ud. es para mi tan apreciable como lo eran las mías para Limneo, quien, si hoy viviera celebraría no menos la sabia correspondencia con Ud" (ACEVEDO DíAZ, 1944, p. 232). Mutis le dedica a Valenzuela la planta con el título de $E l$ Genus Valenzuelia que correspondía a un género nuevo dentro de la flora bogotana. Por su parte, Francisco Antonio Zea (1762-1822) le solicitó al botánico español José Antonio José Cavanilles(1745-1804) que le dedicase una planta "al sobresaliente Dn. Eloy Valenzuela digno de tener lugar en la historia de la botánica” (CARTA n. 10). En la descripción que da Zea de Valenzuela señala que se ha retirado a Bucaramanga

donde se ha dado al estudio de la medicina sin abandonar la botánica. Como cura del lugar tiene mil proposiciones de adelantar sus descubrimientos en todos los ramos de la Historia Natural. Se que escribía la historia de los Juncos dibujando él mismo las láminas de tan hermosas plantas. Sin salir de estos reinos tiene allí abundante materia para muchos escritos. En la flora de Bogotá hay muchos descubrimientos suyos y el Dr. Mutis le ha dedicado un precioso genero. (CARTA n. 11).

Una vez más, es posible que Mutis influyera en la carrera académica de Valenzuela al ser designado por Dn. Pedro Martínez de Pinillos (1748-1809) para que elaborara las Constituciones y el Plan de Estudios de Filosofía para el Colegio de San Pedro Apóstol de Mompox en 1806. Obvio es decir que Valenzuela adelanto en estos documentos su pensamiento sobre la enseñanza de la botánica y la manera cómo él desarrollaría una Expedición Botánica en esta región del norte del virreinato de la Nueva Granada.

Es significativo que en 1808, Eloy Valenzuela, desde su curato de Bucaramanga, solicita al juzgado eclesiástico la dispensa de su residencia para ir a ejercer de rector del Colegio de Mompox para el que ha sido nombrado. Sin embargo, el viaje no lo realizó y nunca llegó a ejercer la rectoría del ColegioUniversidad de Mompox donde hubiese adelantado el vasto proyecto de la Expedición Botánica para la región de Mompox. Consideramos que los hechos políticos de 1810 le impidieron trasladarse a la ciudad de Mompox debido a que 
esta Villa tomó partido por la independencia y Valenzuela en esta época continuaba siendo monárquico.

\section{Las Constituciones del Colegio-Universidad de San Pedro Apóstol - un modelo del pensamiento ilustrado}

Las Constituciones que vamos a analizar fueron presentadas por Eloy Valenzuela el 13 de abril de 1806 (AHNC, tomo 22, fls. 483-515).

El fundador del Colegio D. Pedro Martínez Pinillos le otorgó a Valenzuela plenos poderes para que le representará en Santafé en todo lo relativo a la aprobación de las constituciones de su Colegio de la villa de Mompox. Las gestiones son eficientes porque de inmediato el fundador, su esposa y el Procurador le solicitan al virrey que se nombre a Valenzuela rector y catedrático de filosofía del nuevo Colegio-Universidad de Mompox. El Fiscal dio la aprobación y el virrey le nombró en el cargo solicitado. Como era de esperar de inmediato Valenzuela se lo comunica a su maestro Mutis e inicia las gestiones del permiso para hacerse cargo de la rectoría del citado colegio que, como hemos comentado, no llegó a ejercer.

El rasgo característico que le imprime Valenzuela a las Constituciones fue el de la defensa del estudio de las Ciencias para el reconocimiento científico y de explotación de las riquezas naturales del territorio americano. Igualmente, se refleja en estas Constituciones su identidad con la política del despotismo ilustrado y el movimiento cultural global de la ilustración dentro del eclecticismo de adaptación a la realidad de la zona de Mompox. Como ilustrado se opone al sectarismo religioso y rechaza cualquier manifestación religiosa que distraiga a los alumnos de las tareas de aprendizaje. Además, es relevante su posición monárquica y regalista que detalla en este documento y a su vez el nacionalismo con el apoyo al consumo de los productos nacionales.

Un común denominador de los planes de estudio ilustrados fue el de la crítica al método tradicional. Quizá el más radical y más avanzado, de todos los que conocemos en esta época en el virreinato de la Nueva Granada, sea el de Eloy Valenzuela. En el Plan señala que la enseñanza escolástica "ha ofuscado y 
enmarañado los entendimientos". En las Constituciones se reafirmaba en su posición al plantear que la filosofía de Goudin "atolondra, enmaraña y confunde y así no conviene mucho esmero en estudiarla". Y del método que tradicionalmente se utilizaba, decía que "no ilustraba ni cultivaba las mentes" (Doc. cit. fl. 499 v.).

Las Constituciones se presentan en 12 Títulos. Analizaremos sólo aquellas que tiene que ver con los aspectos más avanzados en relación directa con el pensamiento ilustrado.

El primer apartado que consideramos es novedoso el hecho que se acaben con las informaciones que determinaban, hasta ese momento, en los colegios coloniales que sólo se permitía el ingreso a los de raza blanca. Se dice: "ha de estar patente a todo el mundo. Se han de admitir ricos y pobres, blancos mulatos, menestrales y aprendices, de todos los oficios y hasta los muchachos descalzos, con tal que no estén sucios ni contagiados. El maestro cuidará de separarlos, en bancos o mesas distintas" (Doc. cit. fl. 483).

El aspecto que hemos señalado del cambio que realizó a las informaciones tradicionales se refiere al hecho de no pedir "la hidalguía ni limpieza de sangre." Se especificaba que "si sus padres o abuelos han sido negros de raza, o esclavos de condición, con cuyo favorable despacho bastará para que sean admitidos al colegio y tratados como los otros." Con esta perspectiva se agrega en la nota correspondiente a las informaciones que: "si solamente se admiten nobles, se quedarán muchos sin este beneficio. $Y$ se perderán grandes talentos y habilidades." Pero temiendo que se resintieran los de la clase noble y desampararan el colegio, agregaba que "el remedio es, que a todos esté patente esta carrera del ingenio y del estudio y que separados en clase, no se igualen, ni confundan, las condiciones" (Doc. cit. fl. 488v-489).

Para entender el Plan Ilustrado en su avance frente al ingreso de los mulatos es decisivo analizar el porcentaje de la población y la política que se fue desarrollando frente a la libertad de los esclavos en la modalidad de comprar la misma por parte de ellos o por que su amo la otorgaba por los buenos servicios.

El espíritu nacionalista se encuentra en el capítulo referente al 'alimento diario'. Recomienda el uso del pastel de hoja o el buñuelo para fomentar la "industria de las negras pasteleras." Por otra parte prohibía el uso de té y el café 
por ser productos extranjeros. En cambio, señala como bebida obligatoria el chocolate porque: "es sin contradicción mejor bebida que aquéllas y es de nuestra propia cosecha. Su mayor consumo redunda en beneficio de nuestra agricultura, por eso no más le desprecian los extranjeros." Es importante apuntar que reduce de tres a uno el número de meses de vacaciones por considerar que "es mucha pérdida de tiempo y demasiado descanso aun para los trabajadores de hacha y machete; es convidarles con la flojera cuando se les había de enseñar la aplicación laboriosidad y constancia." (SOTO ARANGO, 1994, p. 223-242).

En el capítulo del estudio y distribución de horario además de lo señalado, específica la jornada de estudio y la cátedra de filosofía, la de música, la de dibujo y hasta el juego de la pelota y el de la raqueta. Considera prioritario el primer año de estudio enseñarle al estudiante la elaboración de cartas personales, mercantiles, letras de cambio y "todo uso de comerciantes" con el objeto que si abandonaba los estudios al finalizar ese año por lo menos este ciudadano podría trabajar de oficial de una contaduría. Eloy Valenzuela señala con detalle cómo deben ser los exámenes parciales y el rigor del aprendizaje, que debe ser comprobado día a día, en el capítulo séptimo de las Constituciones. El examen se presenta al final de la jornada tomando la modalidad de una tertulia entre profesor y estudiante.

Otra aportación, no sólo en cuanto a la peculiaridad, sino también en lo que significaba en el juego de poderes políticos del Virreinato es el referente a la provisión de las cátedras. En efecto, la condición de eliminar el espíritu de partido o el de no favorecer a los egresados del Colegio-Universidad de Mompox van a diferenciar estas Constituciones de las de los colegios y universidades de Santafé. De ahí que, para la posesión, no se exige juramento alguno "mucho menos de seguir determinada escuela o partido." Indica, que lo contrario es un abuso que

ha perjudicado mucho a las ciencias en España y en otras comunidades que se dividen en Tomistas, Escotistas, Javieristas, etc. Jamás los de un partido han podido convertir a los de otro y esto prueba, o que van distantes de la verdad o de la buena fe; lo cierto es que nada interesan al beneficio común y que sus contiendas ni siquiera divierten como las del Quijote. (Doc. cit. fl. 499). 
Asimismo, por las razones ya argumentadas el concurso de catedráticos se determina que sea público y la convocatoria se hará en todo el país. La terna saldrá de la votación que realicen los miembros de la Junta y colegiales y la elección final la realiza el real patronato.

Hemos anotado que en estas Constituciones conviene destacar que prima el sentimiento civil al religioso. Se disminuye las horas de rezo al ponerse media por la mañana y la otra media por la tarde. Pero lo más importante para Valenzuela de las devociones prescritas es "la aplicación al trabajo." En este punto la más importante novedad es la introducción en la enseñanza de los catecismos civiles el que se debería dar "junto o después de aquel." Por lo visto si el hombre necesitaba saber lo necesario para salvarse también era substancial el estudio del comportamiento en la sociedad. Por consiguiente, lo valores sociales, entre otros, el de la honradez frente a la estafa eran prioritarios en un buen ciudadano.

Por otra parte, una vez aprobado, el real Colegio-universidad, el virrey procedió a nombrar los profesores previa oposición que hicieron a los cargos. La administración de los dineros quedó en la compañía mercantil Pinillos y sobrinos con un capital permanente de 120 miles de pesos.

Los dineros se dispusieron de la siguiente manera: "Para los gastos que demandaba el funcionamiento de este plantel destinó sesenta y siete mil seiscientos pesos, cuyos réditos al 5\% anual, que se comprometía a satisfacer oportunamente y con todas las garantías convenientes, la razón social 'Pinillos y sobrinos' daban lo necesario para pagar el rector y el regente de estudios 250 pesos; al vice-rector 100 pesos; a los dos maestros de primeras letras 220 pesos; a los catedráticos de latinidad, filosofía y teología, leyes y cánones 300 pesos a cada uno; al de medicina 400 pesos; al de dibujo 450 pesos; para premios que estimulasen la aplicación de los jóvenes 100 pesos; finalmente 480 para seis becas a rezón de 80 pesos para cada colegial, asignando 300 pesos para un médico con obligación de asistir a las enfermerías del hospital-hospicio; 200 pesos para un boticario y otro tanto para un capellán. (La Voz de Mompox, 29 mayo 1932).

La Universidad se instaló con las normas de rigor el 29 de agosto de 1809 . Interinamente, hasta que Valenzuela ocupara el cargo de rector y catedrático, se nombró al abogado de la Real Audiencia José María Gutiérrez y Cabiedes quien a su vez desempeñó el cargo de vice-rector y catedrático de filosofía y por lo 
tanto le correspondió la lección inaugural del curso académico. Gutiérrez y Cabiedes se había distinguido en su época de estudiante por la exposición que realizó en las conclusiones públicas. También, es de resaltar su participación en la tertulia del Buen Gusto en la ciudad de Santafé. Su nombramiento se reseñó en la época de la independencia, en el Correo del Orinoco, de 29 enero de 1820, de la siguiente manera:

Gutiérrez fue recibido por la Audiencia en el número de abogados, y el Virrey le confirió luego una comisión muy importante para la villa de Mompox, nada menos que para poner en planta el Colegio Universidad que allí se había erigido por Cédula Real á expensas del filántropo español Dn. Pedro Pinillos, hombre bien hechor de aquel país [...]

De todas maneras es importante apuntar que desde el 29 de julio de 1806 el virrey había dictado el edicto del nombramiento de todos los catedráticos, rector y vice-rector.

La Universidad funcionó en el antiguo colegio de los Jesuitas. Sus labores duraron poco tiempo debido a que se clausuró en 1811 y sólo se reabre en 1823 bajo la rectoría del Pbro. Luis José Serrano Díaz. En la misma edicción de 29 de enero de 1820, d'el Correo del Orinoco se reseña el cierre cuando se comenta la biografía de Gutiérrez, se dice: "Gutiérrez cumplió exactamente con su encargo; y el establecimiento se hubiera adelantado mucho, si no se hubiese sobrevenido la revolución de la Nueva Granada, que obligó al director a partir a la capital con otro joven maestro de leyes, compañero de su fortuna”. Este Colegio sufrió los avatares de las luchas políticas en el país y por este motivo sufrió cuatro cierres más en: 1840 a 1845; 1858 a 1872; 1895 a 1896; 1900 a 1905. Finalmente, en 1936 por medio de la Ley 179 se le da el carácter de Instituto Nacional.

\section{Conclusión}

La aprobación Real del Colegio-Universidad de San Pedro Apóstol, localizado en la villa de Mompox, sólo tiene una explicación por estar situado en una Villa de un comercio floreciente y por que el promotor, Dn Pedro 
Pinillos tenía los apoyos en la Corte y el dinero suficiente para que le dieran esta prerrogativa.

El carácter Ilustrado a las Constituciones se las dió Dn. Eloy Valenzuela, primer sub-director, de la Real expedición Botánica. La aplicación de las mismas, sin oposición local, se debió al hecho que no se encontraba ninguna comunidad religiosa regentando estudios en la villa. Los únicos habían sido los jesuitas que fueron expulsados en 1767. Por otra parte, es relevante señalar que el nuevo colegio-universidad no tenía problemas de financiación porque esta situación la había dejado resuelta Dn. Pedro Pinillos.

La nueva institución de carácter civil bajo el patronato del virrey y administración del Cabildo Civil se convirtió en la única universidad que logró aprobación real y aplicación de sus estatutos Ilustrados en el periodo colonial en el virreinato de la Nueva Granada. Presentó el sello de sumisión a la momarquía y un estilo religioso alejado de la beatería.

En definitiva, la primera universidad del Caribe colombiano, presentó unas características que fueron avanzadas en su época y que aún hoy en día siguen teniendo vigencia como: el método de enseñanza-aprendizaje; la educación experimental; las visitas académicas al extranjero; el ingreso por méritos académicos a los estudios y a la docencia y el estilo nacionalista en las reglamentación de la vida cotidiana.

ABSTRACT: This work pretends to analyse the organization process and the approbation of the University-School of San Peter Apostle that was approved by Real Order in 1806 at Mompox Ville. The idea is to demonstrate how that institution presents characteristics of a constitution elaborated by Eloy Valenzuela. On the other hand, the king approved a new university-school on account of political influence of Don Pedro Pinillos and by the offer of money to Spanish crown. The article is based on social history's methodology according to primary documentations was searched at General Archive of Colombian Nation and General Archive of Spanish Indians.
KEY WORDS: colonial university; enlightenment reforms; constitutions; Colombian Caribbean. 


\section{BIBLIOGRAFIA}

ACEVEdo DíAz, M. Genio y figura del doctor Eloy Valenzuela. In: Estudio. Órgano del Centro de Historia de Santander, v. 13, n. 155. Bucaramanga, oct. 1944.

Brito Figueroa, Federico. Historia económica y social de Venezuela, Tomo III, Caracas: Universidad Central de Venezuela, 1987.

Cifuentes, Luis. En Defensa de la Universidad Estatal Chilena. Ciencia al Día Internacional, v. 1, n. 1. Santiago de Chile, abr. 1998.

Conde Calderón, Jorge. Espacio, sociedad y conflictos en la Provincia de Cartagena - 1740-1815. Barranquilla: Fondo de Publicaciones de la Universidad del Atlántico, 1999.

Documentos. Mutis y la Expedición Botánica, Bogotá: Ancora Editores, 1983. Fals Borda, O. Mompox y Loba. Bogotá: Carlos Valencia, 1979.

FERnÁNDEZ DE PIÑEREZ, M. Unas vidas novelescas y un sacrificio glorioso. Mompox: Tipografía el Esfuerzo, 1967.

Fedelman, M. El Siglo XVIII. In: Cuadernos de Estudio 22, Buenos Aires, 1972.

GARRIDO, Margarita. Reclamos y representaciones. Bogotá: Banco de la República, 1993.

Gutiérrez de Piñerez, E. (s/f): La fundación de Mompox. Mompox.

HERR, Richard. España y la revolución del Siglo XVIII. Madrid: Editorial Aguilar. 1964.

Hernández de AlbA, Guillermo. El Colegio San Pedro Apóstol en Mompox y su fundador don Pedro Pinillos. In: Estudios Históricos. Bogotá: Talleres de Ediciones Colombia, 1926.

Hernández De AlBA, Guillermo. Archivo Epistolar del sabio naturalista don José Celestino Mutis. Cartas al sabio Mutis, letras H-Z, v. IV. Bogotá: Editorial Nelly, 1975. 
IHEAL - Institut des Hautes Études de l'Amérique Latine. Université de la Sorbonne Nouvelle. Paris, 1994.

LUKÁCS, György. Sociología de la Literatura. Barcelona: Ediciones Península, 1989.

Marins, Paulo. Habitação e vizinhança: limites da privacidade no surgimento das metrópoles brasileiras. In: SEVCHENKO, N. (Org.). História da vida privada no Brasil, v. 3. São Paulo: Companhia das Letras, 1998, p. 131-214.

Minguet, Charles (1985): Alejandro de Humboltd historiador y geógrafo de la América española, v. II. México: UNAM, 1985.

Morin, Edgar. Os sete saberes para a educação do futuro. Colecção Horizontes Pedagógicos, n. 87. Lisboa: Instituto Piaget, 2002.

Introduction à la pensée complexe. Paris: ESF, 1990.

OCAMpo López, Javier. Historia básica de Colombia. Bogotá: Plaza \& Janes, 1984.

Otero de Costa, E. Escritos del padre Valenzuela. In: Estudio. Órgano del Centro de Historia de Santander. Bucaramanga, año III, n. 30-31, 1934.

PeÑas Galindo, D. Efémeris de Mompox. Cartagena: Espitía Impresores, 1987.

Restrepo, José Manuel. Historia de la Revolución en Colombia. Medellín: Editorial Bedout, 1974.

ROUQUIÉ, Alain. Integristes et militaires: les tentatives du national-catholicisme en République Argentine. In: MINI-COLOQUE, 1, Les Organisations Religieuses en tant que Forces Politiques de Substitution (Le cas des régimes non-pluralistes conteporains), Paris, 27-28 oct. 1972. Anais. Paris: Centre d'Étude des Relations Internationales, 1972. Mimeo.

Pérez Ayala, J. M. Antonio Caballero y Góngora, virrey arzobispo de Santa Fe 1723-1796. Bogotá: Imprenta Municipal, 1951.

Pérez Arbelaez, E.; Acevedo Díaz, M. Apuntamientos. Primer diario de la Expedición Botánica del Nuevo Reino de Granada por V. E. Agregado científico de ella, el cual comprende desde el día 29 de abril de 1783 hasta el día 8 de mayo de 1784. Bucaramanga, Biblioteca Santander, v. XXI, y en Instituto Colombiano de Cultura Hispánica (1983). Bogotá, p. 458. 
República Argentina. Constitución. Constitución de la Nación Argentina. Buenos Aires: Kapelusz, 1994.

Salcedo Del Villar, P. Apuntaciones historiales de Mompox. Cartagena, Gobernación del Departamento de Bolívar, ed. 1. Santa Fe de Bogotá, 1939.

Silva FilHo, R. L. L. Minha experiência como Reitor da USP e da Universidade Mogi das Cruzes. In: Revista ADUSP, n. 9, abril 1997.

Soto Arango, Diana. Mutis: filósofo y educador. Bogotá: Universidad Pedagógica Nacional, 1989.

. La Ilustración en las Universidades y Colegios Mayores de Santa Fe, Quito

y Caracas. Bibliografía crítica y fuentes. Bogotá: Universidad Pedagógica Nacional, 1994.

La Ilustración española y la reformas educativas en el Virreinato de la Nueva Granada. In: Historia de la Relaciones Educativas entre España y América. V Coloquio Nacional de Historia de la Educación. Sevilla: Universidad de Sevilla, 1988, p. 57-67.

Polémicas universitarias en Santa Fe de Bogotá. Bogotá: Universidad Pedagógica Nacional, 1992.

Soto ARAngo, Diana; Arboleda, Luis Carlos. Introducción de una cultura newtoniana en las universidades del virreinato de la Nueva Granada. Recepciòn y difusión de Newton en la Nueva Granada, en colaboración con Luis Carlos Arboleda, en Recepción y difusión de textos Ilustrados. Intercambio científico entre Europa y América en la Ilustración. Editores académicos: Diana Soto Arango, Miguel Angel Puig-Samper , Martina Bender y Marìa Dolores Gonzàlez Ripoll. Madrid, Colecciòn La Ilustraciòn en América Colonial, v. III. Rudecolombia, Universidad de Halle, Colciencias, Dirección de Investigaciones. Universidad Pedagógica y Tecnológica de Colombia. Ediciones Doce Calles, Universidad de León, 2002, p. 203-216.

Los estudios de Botánica en los planes ilustrados del virreinato de la

Nueva Granada. Revista AsCLEPIO de Historia de la Ciencia del Consejo Superior de Investigaciones Científicas. Madrid, v. XLVII, n. 2, 1995, p. 113-137. 
Soto ARANGo, Diana; Uribe, Jorge Tomás. La Ilustración en el virreinato de la Nueva Granada. In: Universidad e Ilustración en América. Nuevas perspectivas. Edición Coordinada por María Cristina Vera. Universidad de Córdoba. Córdoba, Argentina, Universidad Nacional de Córdoba 2002, p. 131-158.

Soto ARANGO, Diana. La política del 'despotismo ilustrado' en la educación superior en el virreinato de la Nueva Granada, en Revista SYNTHESIS. Cadernos do Centro de Ciências Sociais. Universidade do Estado do Rio de Janeiro, 2002, p. 19-28.

VARGas Lesmes, Julián. Historia de Bogotá. Conquista y Colonia, v. II. Bogotá: Salvat Villegas Editores, 1989.

Zambrano Arias, Alfredo; Miranda de Leon, Pablo. Don Pedro Martínez de Pinillos en Mompox. Sincelejo: Compugraficas, 1989.

\section{ANAIS}

ANALES Del Estado De Bolívar, (s/f): Estadística de Mompox.

Archivo General de Indias - AGI. Sección Quinta, Audiencia de Santa Fe, leg. 759. Archivo Cavanilles. Archivo Real Jardín Botánico - ARJB. Carta n. 10 [numeración nuestra].

Archivo Real Jardín Botánico de Madrid - ARJB. Sección Mutis, Serie AA, n. 455.

Constituciones para el Colegio de San Pedro Apóstol de Mompox. Las firma Pedro Martínez de Pinillos, fundador del Colegio, pero fueron elaboradas por el presbítero Eloy Valenzuela, Mompox, 13 de abril de 1806. Archivo General de la Nación de Colombia (AGN). Sección Colonia, Fondo Conventos, v. 22, f. 483-515.

Lista de estudiantes matriculados en el Colegio de San Bartolomé. Archivo General de la Nación, Fondo Colegio San Bartolomé, v. 11.

Padrón de la Provincia de Cartagena. Año de 1780, en Archivo General de la Nación de Colombia. Sección Colecciones. Fondo Ortega Ricaurte. Censos 1, caja 37, documento 11 .

Archivo General de la Nación de Colombia (AGN). Sección Colonia, Fondo Colegios, v. VI, f. 518v. 
Archivo General de la Nación de Colombia $(A G N)$. Sección Colonia, Fondo Conventos, v. 22. BNC, Sección Libros Raros y Curiosos, Protocolo de Instrucción Pública - 1672-1818, n. 338, f. 298-309.

Biblioteca Nacional de Colombia, en adelante BNC. Sección Libros Raros y Curiosos, Manuscritos. Pieza 22, f. 505-531.

La ley 163 de 1959 declara la ciudad de Mompox Monumento Nacional.

\section{BOLETINS}

Boletines Historiales de la Academia de Historia de Santa Cruz de Mompox

Informaciones de Don. Eloy Valenzuela, para su ingreso en el Colegio Mayor del Rosario, Santa Fe, 20 de octubre de 1770. Archivo Colegio Mayor del Rosario en adelante $A C M R$, v. 119, f. 267-270.

ICFES.(1981): Plan propuesto por la Junta de Estudios de 1779, en Compilación de normas de educación superior, La Colonia. p. 120.

ACMR, v. 125, libro $1^{\circ}$ de Colegiales, v. 124, f. 7-178.

Biblioteca Nacional de Colombia - BNC, Libros Raros y Curiosos, Instrucción Pública, n. 13.531, f. 41yv.

\section{Periódicos}

Correo del Orinoco, n. 50. Angostura, sábado, 29 enero 1820.

La Voz de Mompox. Colegio Universidad de San Pedro Apóstol. Semblanza del fundador don Pedro de Pinillos. n. 17. Mompox, 21 mayo 1932.

. Fundación del Colegio-universidad de San Pedro Apóstol. n. 18. Mompox, 29 mayo 1932.

. Constituciones de la Universidad. n. 19. Mompox, 4 jun. 1932. . Apéndice a la monografía de la Universidad. n. 20. Mompox, 11 jun. 1932.

Semanario del Nuevo Reino de Granada. Santa Fe de Bogotá, 8 enero 1809. 